\title{
INTRODUCTION OF THE METHODOLOGICAL STEPS OF TRANSPLANTING A NEW NATIONAL BLACKSPOT MONITORING SYSTEM
}

\author{
Tamás Berta ${ }^{1}$ \\ ${ }^{1}$ Road Safety Centre, KTI Institute for Transport Sciences Nonprofit Ltd., Budapest, Hungary \\ Received 6 October 2016; accepted 2 March 2017
}

\begin{abstract}
The aim of the paper is to introduce the most important steps of a methodology focusing on the transplantation of an up-to-date national system responsible for monitoring traffic accident blackspots. Blackspot analysis methodologies can be based on ranking locations by accident rate (accidents per vehicle-kilometers or per entering vehicles), or using accident density (acc/ km/year or acc/year) or using a combination of the two. Accidents occur with higher density at these relatively high-risk sites. The paper sums up the most important steps of transplanting a new methodology, which contains the revision of the existing methodology, analysis of data, countermeasure development, investigation of technical specifications and monitoring.
\end{abstract}

Keywords: traffic safety, road safety, blackspots, high risk sites.

\section{Introduction}

The main objective of the article is to introduce the most important step of introducing a national wide black spot analysis and treating program. Hauer (1996) wrote that blackspot analysis methodologies can be based on ranking locations by accident rate (accidents per vehicle-kilometers or per entering vehicles), or using accident density ( $\mathrm{acc} / \mathrm{km} /$ year or acc/year) or using a combination of the two. The problem can also be defined as an exploratory spatial data analysis problem: defining the location and the length of black zones. In this approach local spatial autocorrelation indices a decomposition of the global Moran index or kernel estimation can be applied, both methods differentiate local risk and generate a smoothing of the empirical process. Although each method starts from different conceptual approaches, both may provide quite similar results under a specific choice of parameters and lead to a definition of non-contiguous black zones. Based on the results of The Bureau of Transport and Regional Economics of Australia (2001) locations are in general classified as blackspots after an analysis of the level of likelihood of an accident eventuating at each location. At some of the locations, the accident probability is higher than the average accident probability in the neighborhood areas. Accidents occur with higher density at these relatively highrisk sites (Török, 2015). Sites that have a high number of accidents are classified as locations with high accident density or

${ }^{1}$ Corresponding author: berta.tamas@kti.hu 
blackspot sites. Locations with possible dangerous facilities are often defined as grey spots. It is a crucial issue in a national level to define the adequate methodology considering data availability, resources and constrains (Geurts et al., 2003).

\section{Revision of the Existing Map of Blackspots}

Usually blackspot maps are available in every country, however in the road safety field it is always a crucial task to introduce an updated methodology and with the new methodology a new map of black spot. To do the complete revision, in the first step it is necessary to evaluate the previously applied background methodology. It is an important objective of this task to identify the methodology of blackspot analysis in the national safety system fitting to available reliable data, resources and the expected accuracy especially considering that in literature there is no universally accepted definition. Finally this process has to be completed by a national guidebook for Blackspot analysis however it is always a great challenge to bridge the lack of national acceptance of the recommended methodology.

In the next step to review the new map of blackspots it is necessary to evaluate the selected locations of the new map of blackspots. To do this, the results must be compared to other national project results such as high-risk sites indicated by national wide implemented international projects (e.g. SENSOR project). In accordance with EuroRap (Török, 2014) methodology the large majority of fatal and serious crashes occur outside major towns and cities, EuroRAP Risk Mapping concentrates on rural roads. Typically national programmes map higher tier road networks first, where data are most often available, developing to regional networks over time. The aim is to include the network where large numbers of people are being killed and seriously injured. As a result of this task, the map of complementary high risk locations based on the results of previous researches and other projects should be provided although it is always a real risk in this field the available data is not sufficient.

To approach the blackspot problem from a subjective point of view, it is also important to involve local experts in the investigation. In the frame of the blackspot analysis, focus groups need to be organized to select the most critical sites of the network which should be inspected and further evaluated. Focus groups can serve a reliable input to evaluate the results of the previously introduced methodological steps. This can help us to consider local experts' recommendations although sometimes it is not easy to make local experts to cooperate.

After evaluating background methodology, the results and the comparison with other projects of new blackspot maps and the results of expert focus groups the next step is to merge the results to archive a reviewed blackspot map and a consistent and coherent model which is applicable to identify locations with higher accident and injury risk. With this the finalized map of high risk locations can be provided.

\section{Analyzing the Associated Crash History Data, Verifying and Investigating the Site for Identifying Causal Factors}

It is an important step of analyzing crash history data to investigate the methodology of the data collecting process. It is including the analysis of parameters of the data, 
with special attention on identifying the locations (GPS coordinates), types, causes and characteristics of accidents and data of the involved people (age, influence, vehicle type, etc.). As an outcome of this process it is necessary to develop the methodology of data acquisition in order to get valid, reliable data for further analysis. As a result of this work, map of the national accident data collecting processes has to be provided. Deficiency of data availability can be an important barrier of this task.

In the next step the analysis of spatial distribution of accidents and identification of blackspots by accident causes should be carried out (Török et al., 2014). The main causes have to be separated in crash history data. It is also a crucial step of the investigation to analyze locations where there is relevant presence of accidents with a specific group of causes by a specified causative group (e.g. drivers, passengers, vehicles, pedestrians, infrastructure, other failures). This process results the map of blackspots based on accident causes.

Thereafter the next process is to analyze the spatial distribution of accidents and identifying blackspots by accident types. Main types have to be separated in crash history data. Investigating locations where there is relevant presence of accidents of a specified type (e.g. inappropriate speed, ignoring rules for overtaking, failure to yield, violating traffic regulations, failure to comply with stop signs and other rules). This process results the map of blackspots based on accident types (Török et al., 2014).

Following this analyzing spatial distribution of accidents and identifying blackspots by accident characteristics have to be provided. Main characteristics have to be separated in crash history data. Investigating locations where there is relevant presence of accidents of a specified characteristic (e.g. collision of vehicles in motion, collision with parked vehicles or obstacles, skidding, leaving the lane, accidents between vehicles and pedestrians, others). This process results the map of blackspots based on accident characteristics.

It is also very important to analyze spatial distribution of accidents and identifying blackspots by age. Different age groups have special driving characteristics and attitudes. Personal data (e.g. age) of responsible drivers has to be collected in crash history data. It is also a highlighted part of the investigation to identify blackspots related to age groups of responsible drivers may appear on special sections of the road network (e.g. younger drivers tend to have a higher risk of accidents due to over speeding on straight, well-built sections) and investigate locations where there is relevant presence of accidents caused by a certain age group. The aim of this task is to prepare the map of blackspots based on the age of the injured person.

Beside age groups severity is also a critical factor in accidents, hence it is unavoidable to analyze spatial distribution of accidents and identify blackspots by the severity of the injuries. Accurate measurement and data collection about the condition of the drivers (e.g. DUI) is the most important factor for determining the potential impact of prevention. As a result of this step, map of Blackspots based on the age of the injured person should be prepared.

Analyzing spatial distribution of accidents and identifying blackspots by vehicle type is a very important substitutional analysis which can help us to define further interventions. 
Vehicle types have to be separated in crash history data. Investigating locations where there is relevant presence of accidents of a specified vehicle type (e.g. trucks, road tractors, motorcycles, bikes). The result of this task is the map of blackspots based on vehicle types.

As the final step of analyzing crash history data from a spatial point of view a detailed analysis of blackspots according to previously investigated factors has to be provided. This includes the investigation of the relationship of the locations and casual factors, the exploration of weaknesses, the selection of locations where potential interventions can have the most favorable effects.

\section{Countermeasure Development and Selection}

The first step to develop a consistent countermeasure toolkit starts with the review of relevant national standards and regulations related to road inspections. The main objective of this task is to create the map of the legal and institutional environment of countermeasure development in traffic safety.

The next step - based on the relation-matrix of national standards and regulations represented in the previous task - is to identify the most important development directions with reference to relevant European directives, especially considering directive on Road Infrastructure Safety Management (2008/96/EC). This task should focus on the comprehensive adaptation of the road safety inspection methodology into the national framework, providing a methodological background for evaluating the current infrastructure network based on road characteristics. Safety ranking is also extremely important to adopt in the national safety management process based on the methodology of relative accident rate and index of potential for improving safety.

The final step is to identify appropriate instruments to eliminate major factors contributing to risks in the identified locations. Interventions should be selected based on the selected sites, considering possible low cost measures and investmentdependent interventions (e.g. roundabouts). This step should be closely connected to the detailed design development, which will be introduced in the next chapter, since potential instruments identified in the next chapter should provide the basis for the development of local countermeasures.

The final step in this activity is to define comprehensive interventions to reduce or eliminate risk factors. This phase focuses on municipal or national programs as opposed to addressing local risk factors. The outcome of the countermeasure development process should be the national guideline for the proper intervention toolkit.

\section{Technical Specifications, Drawings and Bill of Quantities for Elimination of Blackspots}

For detailed design development, the first step is to evaluate the existing national guidebook, standards and regulations related to the elimination of blackspots. In this activity, the mapping of relevant documents is carried out, especially considering national documents concerning technical specifications, drawings and bill of quantities for the elimination of 
blackspots. After defining the matrix of the relevant documents, the next step is to identify the most important infrastructure interventions addressing local safety risk. This list should provide the contents of the detailed technical specification considering available international references (Elvik et al., 1997). As a result of this step map of existing technical specifications, drawings and bill of quantities for elimination of blackspots is prepared.

To support the full planning process related to the elimination of blackspots it is crucial to assign cost values to listed instruments. The definition of cost values should be based on two pillars. On the one hand, international practices and experiences (Holló et al., 2010; Wegman et al., 2005) should be reviewed, and on the other hand, national infrastructure investment data should be collected focusing on safety improvements. In the end of this task national cost matrix related to intervention toolkit should be produced.

The final step of detailed design development is to define the expected benefits of interventions to define Benefit Cost Ratio (BCR) for each possible instrument. The definition of generalized BCR (Andrejszki et al., 2015) can ensure the comparability of the different investment alternatives. The most important outcome of this process is $\mathrm{BCR}$ matrix related to intervention toolkit.

\section{Monitoring Treatments}

The first step, after accurate location identification, is the elaboration of a reliable register of countermeasures. It is necessary to record the location, type, characteristics and cost of investments, because these form the basis of the effectiveness evaluation of countermeasures.
In addition to the registration of data, it is also necessary to evaluate the effectiveness of implemented countermeasures. However, this is a complex task and a given countermeasure will not necessarily reduce all accident types. A good example for this is resurfacing a road section that has good visibility. After this intervention, the average speed of drivers will increase, creating a potential blackspot of accidents. There are several methods for evaluating effectiveness. A simple method is based on control groups: this entails finding locations without any intervention in the last years that are similar to locations where countermeasures have been implemented, and use them as control groups. The aim of the analysis is to model the trends that would occur without any interventions to create a baseline, which can then be compared to the crash history data. Of course there are more complex methods that can be used for evaluation of effectiveness like monitoring based on hypothesis testing using chi-square tests. Finally evaluation toolkit for implemented countermeasures will be provided.

After the evaluation of effectiveness, countermeasures can be ranked by effectiveness. The ranking will be supported by statistics on previously applied countermeasures. Cost can also be used as a parameter of the ranking, making interventions comparable from a cost effectiveness point of view, which results the ranking of evaluated countermeasures. After this reviewing technical specifications, and drawings; and elaborating proposals for improving the road safety impacts of the least effective countermeasures should be carried out. Based on this step the recommendation toolkit can be completed focusing on technical specifications based on the revision of the previously carried out evaluation. 


\section{Conclusions}

The main objective of the article is to introduce the most important step of introducing a national wide black spot analysis and treating program. In the frame of the blackspot analysis, focus groups need to be organized to select the most critical sites of the network which should be inspected and further evaluated. Following this analyzing spatial distribution of accidents and identifying blackspots by accident characteristics have to be provided. Main characteristics have to be separated in crash history data. Investigating locations where there is relevant presence of accidents of a specified characteristic (e.g. collision of vehicles in motion, collision with parked vehicles or obstacles, skidding, leaving the lane, accidents between vehicles and pedestrians, others). This process results the map of blackspots based on accident characteristics. The next step is to identify appropriate instruments to eliminate major factors contributing to risks in the identified locations. Interventions should be selected based on the selected sites, considering possible low cost measures and investmentdependent interventions (e.g. roundabouts). This step should be closely connected to the detailed design development, which will be introduced in the next chapter, since potential instruments identified in the next chapter should provide the basis for the development of local countermeasures.

As it was previously described, the following step of detailed design development is to define the expected benefits of interventions to define BCR for each possible instrument. According to (Andrejszki et al., 2015), the definition of generalized BCR can ensure the comparability of the different investment alternatives. Therefore, the most important outcome of this process is $\mathrm{BCR}$ matrix related to intervention toolkit.

After the evaluation of effectiveness, countermeasures can be ranked by effectiveness. The ranking will be supported by statistics on previously applied countermeasures. Cost can also be used as a parameter of the ranking, making interventions comparable from a cost effectiveness point of view, which results the ranking of evaluated countermeasures. After this reviewing technical specifications, and drawings; and elaborating proposals for improving the road safety impacts of the least effective countermeasures should be carried out. Based on this step the recommendation toolkit can be completed focusing on technical specifications based on the revision of the previously carried out evaluation.

\section{References}

Andrejszki, T.; Török, Á. 2015. New pricing theory of intelligent flexible transportation, Transport 1-8.

Elvik, R.; Mysen, A.B.; Vaa, T. 1997. Handbook of Traffic Safety (in Norwegian: Trafikksikkerhetshåndbok). Institute of Transport Economics (in Norwegian: Transportøkonomisk institut - TØI), $3^{\text {rd }}$ edition, Oslo, Norway.

Geurts K.; Wets. G. 2003. Black Spot Analysis Methods: Literature Review. Limburgs Universitair Centrum. 30 p.

Hauer, E. 1996. Identification of sites with promise, Transportation Research Record: Journal of the Transportation Research Board 1542: 54-60.

Holló, P.; Eksler, V.; Zukowska, J. 2010. Road safety performance indicators and their explanatory value: A critical view based on the experience of Central European countries, Safety science 48(9): 1142-1150. 
The Bureau of Transport and Regional Economics of Australia. 2001. The Black Spot Program 1996-2002: An evaluation of the first three years, Australia. 254 p.

Török, Á. 2014. Safety analysis of foreign traffic from Visegrad countries on the Hungarian network, Periodica Polytechnica. Transportation Engineering 42(2): 153.

Török, Á. 2015. Analysing the Connection of Hungarian Economy and Traffic Safety, Periodica Polytechnica. Transportation Engineering 43(2): 106.

Török, A.; Török, A.; Heinitz, F. 2014. Usage of Production Functions in the Comparative Analysis of Transport Related Fuel Consumption, Transport and Telecommunication Journal 15(4): 292-298.
Török, Á.; Török, Á. 2014. Macroeconomic analysis of road vehicles related environmental pollution in Hungary, Central European Journal of Engineering 4(2): 186-191.

Wegman, F.; Eksler, V.; Hayes, S.; Lynam, D.; Morsink, P.; Oppe, S. (Eds.). 2005. SUNflower+ 6. A comparative study of the development of road safety in the SUNflower+ 6 countries. SWOV Institute for Road Safety Research, The Netherlands. 83 p.

2008/96/EC (2008). DIRECTIVE 2008/96/EC OF THE EUROPEAN PARLIAMENT AND OF THE COUNCIL of 19 November 2008 on road infrastructure safety management. Available from internet: <http:// eur-lex.europa.eu/eli/dir/2008/96/oj>. 